\title{
A New Way Forward in the Emergency Department
}

\author{
Evan S. Schwarz ${ }^{1} \cdot$ JoAn R. Laes ${ }^{2} \cdot$ Timothy J. Wiegand $^{3}$ \\ Received: 31 May 2019 / Revised: 31 May 2019 / Accepted: 31 May 2019 / Published online: 5 July 2019 \\ (C) American College of Medical Toxicology 2019
}

Keywords Buprenorphine $\cdot$ Emergency department $\cdot$ Medication-assisted treatment $\cdot$ Addiction

Opioid overdoses are responsible for an increasing number of deaths each year. While many people suffering from an opioid use disorder (OUD) want treatment, access continues to be limited [1]. This is especially tragic given that medication for addiction treatment (MAT [formerly known as medication-assisted treatment]) significantly reduces morbidity and mortality from OUD [2,3]. MAT or specifically opioid agonist therapy utilizing either buprenorphine or methadone eliminates cravings and withdrawal symptoms and allows patients with OUD to feel normal so that they can overcome their illness and put their lives back together. While far from perfect, success and retention in treatment with either medication is vastly superior to abstinence-based approaches [3].

While methadone when used for the management of OUD is heavily restricted due to its risk for misuse and associated adverse events, buprenorphine has changed our ability to manage these patients [4]. Initially developed as an analgesic, it was approved for the treatment of OUD in the USA in 2002 [5]. While it is an opioid, due to it being a partial agonist, it is associated with fewer adverse events and can be titrated more easily than full agonists such as methadone. Not only does this mean that it is safer than medications such as methadone, but also, it can be prescribed out of settings that have not traditionally offered MAT for OUD [5-7]. In fact, many addiction

Supervising Editor: Mark B. Mycyk, MD

Evan S. Schwarz

schwarze@wustl.edu

1 Division of Emergency Medicine, Washington University School of Medicine, 660 South Euclid, Campus Box 8072, Saint Louis, MO 63144, USA

2 Department of Internal Medicine, Division of Addiction Medicine, Hennepin County Medical Center, Minneapolis, USA

3 Department of Emergency Medicine, University of Rochester Medical Center, Rochester, USA providers routinely induce and titrate buprenorphine at home and not in the office.

The emergency department (ED) continues to serve as the front door of the hospital. It is a place that anyone, at any time, for any reason can seek treatment. Yet, this marginalized and stigmatized population has historically not been offered this potentially life-saving therapy in the ED following an overdose, when in extremis or withdrawal or when just requesting assistance. This is in contrast to most all other populations such as patients with diabetes or asthma presenting to the ED with complications of their disease. However, this paradigm can completely change with the administration of buprenorphine in the ED [8]. A study conducted at Yale in 2015 demonstrated the feasibility of this approach [9]. Patients in the ED were successfully induced with buprenorphine, which was associated with drastically improved treatment retention rates at 1 month. Now, that study has been criticized as at 1 year retention rates significantly regressed without a demonstrable difference in terms of retention in treatment between the referral arm, referral and brief intervention arm, and arm that received buprenorphine [10]. However, the three groups were only followed for 12 weeks by the study team at which time the arm that received buprenorphine still was significantly more likely to be in treatment as compared with the other two. After 12 weeks, patients were either weaned off of buprenorphine or referred to other clinics for continuation of treatment, although it is unclear what that entailed. Patients undergoing forced weans or only receiving short-term treatment have worse outcomes than patients receiving long-term MAT [11].

Skeptics raise further concerns that either are not demonstrated to occur, are inaccurate, or are easily overcome. Few skeptics seem to outwardly state that they are against assisting this population as they believe their disease is a moral failing, although this stigma continues to be propagated in the lay media and further spread by politicians $[12,13]$. Frequently, some critics will argue that the ED is already too busy, that this 
is too difficult to do in the ED, or it will increase the length of stays and increase patient volumes in EDs that are already overcrowded and under-resourced [14]. They also worry about diversion and lack of long-term resources. While it is important to understand these concerns, it is just as important to address these misperceptions. Induction with buprenorphine is far easier than many other procedures commonly performed by emergency physicians. It is also a far safer medication than others administered in the ED such as heparin, insulin, and other opioids. Additionally, multiple protocols with easy-to-follow directions are free and available online $[15,16]$. While it is possible that some EDs have seen an increase in volume after beginning a buprenorphine program, this is not consistent with most providers' anecdotal experiences. Most patients that could benefit from this treatment are already in the ED, either following an overdose, in withdrawal, or there from a complication of their OUD. However even if more patients presented to your ED, these patients can easily be managed and discharged from the waiting room. Not only is buprenorphine induction not likely to increase the length of stay but it can decrease it. Traditionally, patients presenting in opioid withdrawal spend hours in the ED after failing multiple anti-emetic treatments. With the administration and titration of sublingual buprenorphine, patient's symptoms can be controlled in under an hour. Unlike other mandates and expectations, such as a 1$\mathrm{h}$ sepsis bundle, this practice change can both make emergency providers' jobs easier and improve patient care [17, 18].

Of course just like all opioids, buprenorphine can be diverted, but by prescribing only small amounts for a few days, this risk can be minimized. Just as importantly while we would prefer patients receive treatment under the direction of a physician, thought leaders agree that buprenorphine is much more likely to be diverted to treat withdrawal in patients that are unable to access treatment than to be abused for intoxication $[19,20]$. As such, the solution is to engage options that increase treatment and not to continue to limit it, which paradoxically might decrease the market for diverted buprenorphine as more patients obtain access to treatment. Concerns regarding limited, long-term treatment are legitimate. Though access to long-term treatment has increased, there is still not enough. Instead of bemoaning this limitation, some hospitals have implemented creative solutions such as bridge clinics and telehealth approaches. Encouraging primary care physicians to prescribe buprenorphine would also be advantageous and increase access [21]. Eliminating or at least easing requirements to obtain an $\mathrm{x}$-waiver, the license required to prescribe buprenorphine for OUD, is a needed step to increase the number of physicians prescribing this medication [22]. If nothing else, elimination would further decrease stigma associated with this disease. Finally while we'd prefer patients receiving buprenorphine in the ED to always be linked to treatment, from a pure harm reduction philosophy, even a single day on buprenorphine is 1 day not exposed to heroin or fentanyl and introduces the patient to this potentially life-changing therapy.

Given the importance and energy galvanizing around the treatment of OUD, the American College of Medical Toxicology (ACMT) released a position statement supporting the administration of buprenorphine in the ED (https://www. acmt.net/_Library/Positions/ACMT_Bup_ED_Position Statement_REV.pdf) [8]. The statement is endorsed by both the American Academy of Emergency Medicine (AAEM) and the American College of Emergency Physicians (ACEP). We additionally hope that it will soon be endorsed by the American Society of Addiction Medicine (ASAM). A recent hour-long tweet chat about the position statement received nearly 1 million impressions in only $24 \mathrm{~h}$. We realize this necessary approach is a huge shift from what is occurring in many EDs across the country, but it can literally save lives and prevent the spread of infectious disease. The position statement offers rationale regarding why EDs should implement buprenorphine programs and some of the resources they require to do so. It also serves as a reference for administrators that are still hesitant to do so. Given the toll of opioids and addiction on all Americans and the efforts being made by many of its members, ACMT saw the need to assume a leadership role in advocating for increasing access and improving treatment for this marginalized population that otherwise struggles to consistently have a voice. By drawing attention to one intervention, we hope the position statement will lead to further change and creative solutions. Just as with the combined statement about occupational fentanyl exposures, we hope this position statement clarifies misperceptions and leads to substantial improvements in patient care [23].

The alternative is to continue to only offer harm reduction. While harm reduction is important, it is not sufficient. Treatment and harm reduction, of course, are not mutually exclusive. Syringe exchange and safe consumption sites (or safe injection sites) are associated with decreased rates of infectious disease and increases in patients seeking treatment $[24,25]$. However, syringe exchange is still not legal in many states, and there are no legally functioning safe consumption sites operating in the USA. Naloxone, though, is increasingly available in the USA and aside from the opinions of a small minority is a socially accepted form of harm reduction to both lay people and medical providers [26]. While naloxone distribution is necessary, it is hardly sufficient. A recent study demonstrated that lay access to naloxone resulted in $93.5 \%$ of people surviving an overdose [27]. Tragically, only $84.3 \%$ of survivors were still alive 1 year later. To put this into perspective, the 1-year mortality following an ST-elevation myocardial infarction is $7.3 \%$; the 1 -year mortality following an opioid overdose is $7.5 \%$ [27, 28]. While we must continue to make sure naloxone is readily available to properly resuscitate patients, this cannot be the final or only step. A concerted 
effort must be made to immediately connect patients into treatment. It would be great if that involved transporting the patient directly from the scene to a traditional treatment center for initiation of MAT. However for the time being, the only treatment center that is reliably and always open remains the ED.

Sources of Funding No funding

\section{Compliance with Ethical Standards}

Conflicts of Interest None.

\section{References}

1. Saloner B, Karthikeyan S. Changes in substance abuse treatment use among individuals with opioid use disorders in the United States, 2004-2013. JAMA. 2015;314(14):1515-7.

2. Mattick RP, Breen C, Kimber J, Davoli M. Buprenorphine maintenance versus placebo or methadone maintenance for opioid dependence. Cochrane Database Syst Rev. 2014;2:CD002207.

3. Pierce M, Bird SM, Hickman M, Marsden J, Dunn G, Jones A, et al. Impact of treatment for opioid dependence on fatal drug-related poisoning: a national cohort study in England. Addiction. 2016;111(2):298-308.

4. Kampman K, Jarvis M. American Society of Addiction Medicine (ASAM) National Practice guideline for the use of medications in the treatment of addiction involving opioid use. J Addict Med. 2015;9(5):358-67.

5. Bhatraju EP, Grossman E, Tofighi B, McNeely J, DiRocco D, Flannery M, et al. Public sector low threshold office-based buprenorphine treatment: outcomes at year 7. Addict Sci Clin Pract. 2017;12(1):7.

6. Moore BA, Fiellin DA, Barry DT, Sullivan LE, Chawarski MC, O'Connor PG, et al. Primary care office-based buprenorphine treatment: comparison of heroin and prescription opioid dependent patients. J Gen Intern Med. 2007;22(4):527-30.

7. Stancliff S, Joseph H, Fong C, Furst T, Comer SD, Roux P. Opioid maintenance treatment as a harm reduction tool for opioiddependent individuals in New York City: the need to expand access to buprenorphine/naloxone in marginalized populations. J Addict Dis. 2012;31(3):278-87.

8. Wax PM, Stolbach AI, Schwarz ES, et al. J Med Toxicol. 2019;15: 215. https://doi.org/10.1007/s13181-019-00712-3.

9. D'Onofrio G, O'Connor PG, Pantalon MV, Chawarski MC, Busch $\mathrm{SH}$, Owens PH, et al. Emergency department-initiated buprenorphine/naloxone treatment for opioid dependence: a randomized clinical trial. JAMA. 2015;313(16):1636-44.

10. D'Onofrio G, Chawarski MC, O'Connor PG, Pantalon MV, Busch $\mathrm{SH}$, Owens $\mathrm{PH}$, et al. Emergency department-initiated buprenorphine for opioid dependence with continuation in primary care: outcomes during and after intervention. J Gen Intern Med. 2017;32(6):660-6.

11. Bentzley BS, Barth KS, Back SE, Book SW. Discontinuation of buprenorphine maintenance therapy: perspectives and outcomes. J Subst Abus Treat. 2015;52:48-57.
12. Lopez G. Vox [Internet]. Trumps Top Health Off. Got a basic fact opioid addiction very very wrong. 2017;Available from: https:// www.vox.com/policy-and-politics/2017/5/11/15613258/tom-priceopioid-epidemic. Accessed 25 May 2019.

13. Rosenstein R. Fight drug abuse, don't subsidize it. NY Times 2018. https://www.nytimes.com/2018/08/27/opinion/opioids-heroininjection-sites.html. Accessed 25 May 2019.

14. D'Onofrio G, McCormack RP, Hawk K. Emergency departments a 24/7/365 option for combating the opioid crisis. N Engl J Med. 2018;379(26):2487-90.

15. ED BRIDGE [Internet]. ED BRIDGE. Available from: https://edbridge.org/guide. Accessed 25 May 2019.

16. SHOUT support for hospital opioid use treatment [Internet]. SHOUT Support Hosp. Opioid Use Treat. Available from: https:// static1.squarespace.com/static/5acbce828f51302409d8bdcb/t/ 5ad817f403ce646d1a1f4646/1524111350276/QUICK+GUIDE-+ Buprenorphine+-+04-18-18.pdf. Accessed 25 May 2019.

17. Levy MM, Evans LE, Rhodes A. The Surviving Sepsis Campaign bundle: 2018 update. Crit Care Med. 2018;46(6):997-1000.

18. Kalantari A, Rezaie SR. Challenging the one-hour sepsis bundle. West J Emerg Med. 2019;20(2):185-90.

19. Gold M. The paradox of diverted buprenorphine [internet]. Addict. Policy Forum. (n.d.) Available from: https://www.addictionpolicy. org/blog/the-paradox-of-diverted-buprenorphine. Accessed 25 May 2019.

20. Cicero TJ, Ellis MS, Chilcoat HD. Understanding the use of diverted buprenorphine. Drug Alcohol Depend. 2018;193:117-23.

21. Thirion X, Lapierre V, Micallef J, Ronflé E, Masut A, Pradel V, et al. Buprenorphine prescription by general practitioners in a French region. Drug Alcohol Depend. 2002;65(2):197-204.

22. Auriacombe M, Fatséas M, Dubernet J, Daulouède J-P, Tignol J. French field experience with buprenorphine. Am J Addict. 2004;13(Suppl 1):S17-28.

23. Moss MJ, Warrick BJ, Nelson LS, McKay CA, Dubé PA, Gosselin $\mathrm{S}$, et al. ACMT and AACT position statement: preventing occupational fentanyl and fentanyl analog exposure to emergency responders. Clin Toxicol (Phila). 2018;56(4):297-300.

24. Chan PA, Montgomery M, Marak T, et al. A nearly $50 \%$ decrease in new HIV diagnoses in Rhode Island from 2006-2016: implications for policy development and prevention. R I Med J (2013). 2018;101(8):41-5.

25. Hood JE, Behrends CN, Irwin A, Schackman BR, Chan D, Hartfield K, et al. The projected costs and benefits of a supervised injection facility in Seattle, WA, USA. Int J Drug Policy. 2019;67: 9-18.

26. Doleac J, Mukherjee A. The moral hazard of lifesaving innovations: naloxone access, opioid abuse, and crime. (n.d.) [cited 2019 May 12];Available from: https://papers.ssrn.com/sol3/papers.cfm? abstract id=3135264. Accessed 25 May 2019.

27. Weiner SG, Baker O, Bernson D, Schuur JD. 402 One-year mortality of opioid overdose victims who received naloxone by emergency medical services. Ann Emerg Med. 2017;70(4):S158.

28. Doost Hosseiny A, Moloi S, Chandrasekhar J, Farshid A. Mortality pattern and cause of death in a long-term follow-up of patients with STEMI treated with primary PCI. Open Heart. 2016;3(1):e000405.

Publisher's Note Springer Nature remains neutral with regard to jurisdictional claims in published maps and institutional affiliations. 